\title{
Résumés des Articles
}

Judith Milhous et Robert D. Hume, Un cahier de régie de 1667 pour Loves Crueltie de James Shirley

La collection 'Brotherton' de l'Université de Leeds possède un cahier de régie pour Loves Crueltie de James Shirley qui n'a pas, jusqu'ici, été signalé. Ce cahier prévoit une mise en scène à décors multiples pour la King's Company à Bridges Street et date vraisemblablement de 1667 . Cinq décors différents sont indiqués, et treize changements de scènes. Le texte révèle aussi, en passant, le nom de quatre comédiens (Hart, Hancock, Bateman et 'Abraham' [Ivory]). Toutes les entrées des acteurs et tous les changements de décors sont indiqués par les symboles à l'usage à cette époque (voir notre article). Le texte de la pièce a été annoté par deux scribes restés anonymes. Certaines annotations ont été tronquées, mais presque toutes ont pu être reconstitutées. De nombreuses coupures sont indiquées dans le texte, soit pour raccourcir le spectacle, soit pour le purger de passages jugés scabreux. Ce cahier de régie est le treizième cahier complet connu de la fin du dix-septième siècle en Angleterre et nous reproduisons dans notre article toutes les indications de régie et toutes les coupures de texte.

Steven Earl Forry, L'horrible progéniture de Frankenstein sur scène, de I823 à ${ }_{1} 826$

Trois mélodrames ont scellé le destin de Frankenstein sur la scène du dixneuvième siècle: Presumption; or, The Fate of Frankenstein (1 823) de Richard Brinsley Peake, Le Monstre et le magicien (1826) de Jean-Toussaint Merle et Béraud Antony et The Man and the Monster (1826) d'Henry Milner. Alors que le Frankenstein ( 1818 ) de Mary Shelley renouvelait le mythe de Faust et créait un personnage double aux dimensions byroniennes, baignant dans une atmosphère tragique, les mélodrames eurent recours à l'alchimie et abandonnèrent toute complexité en faveur d'un conflit simpliste opposant Frankenstein, héros funeste, au Monstre, traître de pantomime. La structure fut aussi simplifiée pour obéir à la règle des vingt-quatre heures et les personnages furent réduits à quatre types bien distincts: le héros, le traître, l'héroïne persécutée et le valet comique, joué par l'assistant de Frankenstein, le plus connu étant Fritz. Ces transformations s'intégrèrent aux dramatisations du roman de Shelly au cours du dix-neuvième siècle et, dès le début du vingtième siècle, elles firent partie intégrale du mythe, sur la scène et à l'écran.

Theatre Research International Vol. I I, No. I 
Kathleen Barker, Un tragédien provincial à l'étranger

Charles Dillon (18I9-188I) fut un de ces acteurs britanniques qui cherchèrent gloire et fortune en pays étrangers. De I 86 I à 1867 il fit une tournée mondiale à travers les Etats-Unis, le Canada, l'Australie, la NouvelleZélande et l'Amérique du Sud. Mais des circonstances désastreuses, tant sur le plan personnel que financier, politique, voire météorologique, ne lui permirent pas d'atteindre son but. A cause des malheurs qui le poursuivaient partout, Dillon ne joua pas, comme il l'avait escompté, les grands rôles du répertoire à l'occasion de représentations exceptionnelles et lucratives, mais - bon gré, mal gré - il s'est trouvé au centre de l'activité théâtrale de villes californiennes, australiennes, nouvelles-zélandaises où il était obligé de séjourner plus longtemps que prévu. La conséquence de cet état de choses fut qu'il fit parfois une contribution plus durable à la vie théâtrale de ces pays, sans en retirer le profit pécuniaire espéré. Les biographies des acteurs et actrices victoriens donnent souvent l'impression d'une ascension triomphale, financièrement et artistiquement, grâce aux tournées étrangères. L'histoire de Dillon est fort différente et elle est peutêtre aussi plus proche de la réalité.

Katharine B. Free, Un exemple de théâtre religieux aux Indes: le Bhavāà de Gujarat

Le Bhavāī est une tradition de théâtre folklorique et religieux indien qui survit de nos jours dans les régions de Gujarat et du Rajasthan. Le Bhavāī présente la double particularité d'être dédié à la Déesse-Mère des Indes et d'être irrésistiblement comique (hāsya rasa). Le côté comique de ce théâtre rappelle l'ancienne comédie athénienne et les cycles du Moyen Age qui savaient aussi mélanger saine paillardise et dévotion religieuse. Avant chaque représentation de Bhavāì, les acteurs, exclusivement masculins, méditent et prient selon une coutume ancienne et immuable. Ils dédient leur art et la représentation à la Déesse-Mére, ce qui ne les empêchera pas de jouer des situations obscènes et de proférer des énormités qui choquent parfois le public d'aujourd'hui. Ce public citadin et petit-bourgeois pose un réel danger à la survie du genre. Les acteurs, qui transmettent leur savoir de père en fils, se font aussi plus rares, car les récompenses matérielles sont maigres. Pourtant les artistes qui travaillent actuellement refusent de se soumettre aux goûts du jour pour attirer un plus grand public car le Bhavāì est, avant tout, une offrande traditionnelle à une déesse bien-aimée et les communautés villageoises s'efforcent aussi au maintien de la tradition. 